\title{
Improving the tuberculosis drug development pipeline
}

Authors: Dimitrios Evangelopoulos* and Timothy D. McHugh.

\section{Author's affiliation:}

Centre for Clinical Microbiology, University College London, London, NW3 2PF, UK.

* Corresponding author:

Dr Dimitrios Evangelopoulos,

Email: d.evangelopoulos@ucl.ac.uk

Direct Line: Tel: +442077940500 extension: 31146

\begin{abstract}
Mycobacterium tuberculosis is considered one of the most successful pathogens and drug resistant Tuberculosis (MDRTB) a disease that urgently requires new chemical entities to be developed for treatment. There are currently several new molecules under clinical investigation in the TB drug development pipeline. However the complex lifestyle of $M$. tuberculosis within the host presents a barrier to the development of new drugs. In this review, we highlight the reasons that make TB drug discovery and development challenging as well as providing solutions, future directions and alternative approaches to new therapeutics for TB.
\end{abstract}

\section{Introduction}

Twenty years have passed since the World Health Organisation declared tuberculosis a global health emergency (WHO, 1993). The situation is still bleak with 9 million cases and 1.5 million deaths per year globally (WHO, 2013). This is further exacerbated by development of multi drug resistant tuberculosis (MDRTB), extensively resistant tuberculosis (XDRTB) and now totally resistant tuberculosis (TDRTB) (Udwadia, 2012). The standard regimen, long established and approved by $\mathrm{WHO}$, is effective for treatment of the majority of tuberculosis cases. However, the long treatment duration (6 months), toxicity and interaction with anti-retrovirals leads to poor patient adherence and, consequently, treatment failure. There is no doubt that an improved portfolio of anti-tuberculosis treatments is required; after the introduction of the rifamycins in the 1960's there had been 
no new drug to treat tuberculosis for 30 years. The extent of this problem was highlighted at a stakeholders meeting in Cape Town in 2000 and this meeting reinvigorated the resolve of the drug development community to identify new compounds and drive them through the drug development pipeline (Pablos-Mendez, 2000).

The TB pipeline is flowing as demonstrated by the efforts led by the TB Alliance (Figure 1). For the last quarter of the $20^{\text {th }}$ Century, ad hoc evaluation of the rather sparse flow of new antibacterials contributed little to anti-mycobacterial treatment. Now, in the $21^{\text {st }}$ Century we have compounds entering the pipeline for primary screening as well as completion of phase 3 clinical trials (Zumla et al., 2013; Zumla et al., 2014a). There is much debate about the most efficient way to identify new compounds with activity against Mycobacterium tuberculosis; the description of the M. tuberculosis genome in 1998 opened the door for rational drug design and a targeted approach to key metabolic pathways (Cole et al., 1998; Sams-Dodd, 2005). Alternative strategies include screening compound libraries, whether synthetically produced derivatives (Guzman et al., 2011) or natural compounds derived from plants (Guzman et al., 2012; Guzman et al., 2010; O'Donnell et al., 2009; Osman et al., 2012) or lower order animals such as the marine sponges (Kottakota et al., 2012a; Kottakota et al., 2012b; Sim et al., 2008). These combined approaches have yielded some hits, but progress is slow and so the idea of revisiting and repurposing drugs previously ruled out for treatment of tuberculosis but in use for other disease presentations has gained traction. The imperative of drug resistance has provided a new perspective to the development process; not only a sense of urgency, but a willingness to balance the gains of successful treatment of drug resistant tuberculosis against previously unacceptable adverse events. An example of this is the proposed use of thioridazine (Amaral et al., 2010; Amaral and Viveiros, 2012), an anti-psychotic treatment introduced in the 1960's. In preliminary screening thioridazine was shown to be active against tuberculosis, but at the time its anti-psychotic activity was considered too severe for the drug to be a useful anti-tuberculosis treatment. It has now used effectively in cases of TDRTB (Udwadia et al., 2011).

Drug treatment is only an element in the strategy to control the tuberculosis pandemic; early and effective diagnosis is critical and vaccine development has a significant role (Young et al., 2008). However, improved drug treatment is fundamental to our success. The key challenge in treatment is the length and complexity of the drug combinations that have a proven track record (Zumla et al., 2014a; Zumla et al., 2014b). Standard therapy is rifampicin, isoniazid, ethambutol and pyrazinamide for 2 months (the intensive phase) followed by 4 months of rifampicin and isoniazid (the continuation phase). Whilst exploring new drugs is essential, there is a surprising lack of knowledge about the standard regimen. Its implementation has largely been pragmatic. We know from UK MRC studies that $80 \%$ of patients would be cured with a 4 month regimen, the difficulty is that with current knowledge we cannot predict those that will require a full 6 month course and so in practice the standard regimen over treats the majority of patients (Jindani, 1976). To address this we need biomarkers for prediction of treatment outcome (Wallis et al., 2013). A further 
pragmatic decision made was the dose level for rifampicin; when it was introduced in the 1960's it was an expensive drug and supplies were limited and so the dose level was set at a minimum effective dose and higher doses not explored (van Ingen et al., 2011). We now have considerable knowledge of the safety profile of this group of compounds and animal studies suggested that use of higher doses may shorten therapy (Rosenthal et al., 2012). With this in mind studies have been implemented to evaluate increased doses of rifampicin for safety in the first instance; the PanACEA Consortium study, HIGHRIF has taken the safe dose up to $20 \mathrm{mg} / \mathrm{kg}$ and is now moving from short safety studies to full efficacy evaluation (Jindani et al., 2014).

The tuberculosis pandemic is happening now. Our problem is that drug development is time consuming, this is compounded by a pathogen that has a slow growth rate $(24 \mathrm{~h}$ doubling time compared with $30 \mathrm{~min}$ for $E$. coli) and a complex and unique biochemistry. Furthermore as compounds move down the pipeline we lack suitable biomarkers for success of treatment and so drug evaluation is slow. These are the challenges that the tuberculosis research community face; in this review we aim to describe the challenges and demonstrate ways in which they are being met.

\section{The challenges of TB drug development}

\section{The biology of Mycobacterium tuberculosis.}

Following entry of the bacilli into the human, the mechanisms of innate and acquired T-cellmediated immunity efficiently prevent the spread of the disease (Korbel et al., 2008; van Crevel et al., 2002). However, a percentage of bacilli survive within the host without causing clinical disease for an unlimited period of time; $10 \%$ of these patients having latent infection will develop clinical disease in a future. M. tuberculosis bacilli once in lungs, are internalised by alveolar macrophages or dendritic cells by phagocytosis. However, M. tuberculosis has evolved multiple strategies in order to survive in the harsh environment inside macrophages. One being the bypass of the fusion with lysosomes and that permits intracellular survival of M. tuberculosis (Armstrong and Hart, 1975).

Following initial infection of $M$. tuberculosis within the alveolar macrophages, a proinflammatory response by the macrophages is generated which involves release of cytokines and chemokines including TNF- $\alpha$, CCL2 and IL-18 (Fuller et al., 2003; Rhoades et al., 1995). These signals recruit mononuclear phagocytes and leucocytes from the neighboring blood vessels into the site of infection resulting in the formation of a granuloma. The mature granuloma contains the infected macrophages that are surrounded by mononuclear phagocytes and leukocytes, which in turn are surrounded by a fibrous cuff, made of extracellular matrix material that encloses the structure. Within the granuloma there is a high concentration of foamy macrophages that are rich in lipids (Kim et al., 2010; Russell et al., 2009). The center of the granuloma is believed to contain hypoxic conditions with little nutrient availability (Tsai et al., 2006). M. tuberculosis can persist in granulomas 
for decades (Fenhalls et al., 2002). In 5-10\% of patients with latent tuberculosis the reactivation of tuberculosis will occur when a change of the host immune system eventually leads to the rupture of the granuloma and escape of M. tuberculosis (Marks et al., 2000).

Non-replicating but viable M. tuberculosis cells, as well as cells under hypoxic stress, accumulate triacylglycerol lipids in the lipid bodies (Garton et al., 2008). Fatty acids and host cholesterol acts as an energy source during persistence (Pandey and Sassetti, 2008). Interestingly, reactivation of persistent mycobacteria can be achieved in vitro by incubation of $M$. tuberculosis with resuscitation-promoting factor (Rpf) produced by Micrococcus luteus (Mukamolova et al., 1998). In the M. tuberculosis genome five homologues of $r p f$ have been identified. Even though deletions of each individual rpf gene (Tufariello et al., 2004) as well as all the rpfs (Kana et al., 2008) did not affect the in vitro growth of $M$. tuberculosis (Kana et al., 2008; Tufariello et al., 2004), they proved to be essential for the survival of the pathogen within macrophages (Tufariello et al., 2006). In addition, expression of the genes that encode for Rpf proteins have been demonstrated in tissues from patients with active TB (Davies et al., 2008) suggesting the essential role of this protein family in M. tuberculosis pathogenesis. Furthermore, it has been demonstrated that sputum samples contain a population of non culturable bacilli whose growth is depended upon addition of Rpfs (Mukamolova et al., 2010). The structures of Rpfs show similarity to peptidoglycan hydrolases (Cohen-Gonsaud et al., 2005) signifying a role in the reactivation of the bacteria and cell division by breaking down the units of the bacterial peptidoglycan (Kana and Mizrahi, 2010; Keep et al., 2006).

\section{Complexity of evaluating drugs}

The multifaceted lifestyle that $M$. tuberculosis employs in the human host has several implications for TB drug discovery. The different physiological states in which bacteria are found suggest that we should treat TB infection as a polymicrobial infection and thus the new drugs and drug regimens under development need to be able to act on all phenotypes of $M$. tuberculosis. However, very little is known about the specific physiological state(s) that the TB bacilli are present in the human host. Chemotherapy itself may trigger the bacteria to adopt a new state such as persistence or a drug tolerant phenotype in order to evade bacterial elimination caused by the drug action (Cohen et al., 2013; Keren et al., 2011; Mitchison et al., 2007). It is clear from patient data that the reduction of the bacterial load during chemotherapy follows a biphasic slope (Mitchison and Davies, 2012). It is usually believed that the initial drastic reduction on the number of viable bacilli represents the killing of actively dividing and metabolically active states whereas the second more steady decrease occurs when persistent populations are dying and it is usually long-lasting. The observation that the TB chemotherapy affects the rate of $M$. tuberculosis clearance from the host is not only observed on the standard treatment but also from the recent phase 3 clinical trials such as REMOX-TB with the difference being that the initial phase being a more drastic reduction in the bacterial load on the regimens where moxifloxacin is tested when 
compared to the current treatment (Gillespie et al., 2014). The dynamics of the antimicrobial agents that force the bacteria into different and difficult to eliminate states are very little understood and new research should be focus towards understanding this (Wakamoto et al., 2013).

This phenomenon of different subpopulations of $M$. tuberculosis during infection represents a challenge in TB drug discovery. Whole cell phenotypic inhibitor screening assays will mainly capture $M$. tuberculosis bacteria that are actively dividing and homogeneous. Any possible hits that will result from this approach may not have any effect on the low metabolically active bacteria and as a consequence the hit or developed lead molecule will most likely fail in the downstream clinical trials.

One way that this is currently being applied is to establish various in vitro models that aim to replicate the way low metabolically active or dormant bacilli will react under treatment. These models can be achieved in vitro by limiting either the nutrient availability or by inducing hypoxia to the bacterial cultures. Furthermore growth conditions such as temperature, $\mathrm{pH}$ as well as multiple other stresses will have an effect on the physiological states of the mycobacteria (Betts et al., 2002; Deb et al., 2009; Galagan et al., 2013; Hu et al., 1998; Wayne and Hayes, 1996). Although these dormancy models can replicate several aspects of the $M$. tuberculosis biology, they fail to represent the exact physiological states and transitions that the pathogen undergoes during the hostile host immune defence and thus impose limitations on their use for drug discovery.

\section{Animal models}

Every single lead compound will be first evaluated using an animal model before proceeding into clinical trials. Several animal models have been employed in TB research in an effort to further characterise drug efficacy. Most commonly the mouse model is used followed by guinea pig and rabbit models. In addition, zebra fish models have also been utilised especially in the drug discovery, as they help to visualize the first steps of the TB pathogenesis as well as allowing a high throughput approach without complicated ethical approvals. Although there are different animal models for TB, not a single one of them is a representative of the pathogenesis that we see in human hosts (Young, 2009) and so we need to use a range to capture specific characteristics of the TB infection. However because of the complex physiology in human disease animal models can sometimes be poor in predicting drug efficacy; linezolid is one example where in vitro and in vivo data were not predictable enough of the drug efficacy in humans with XDRTB.

Mouse models are commonly used as they are low cost, allow rapid experimental procedures and there is availability of a wide range of immunological reagents as well as recombinant animals with diverse genetic backgrounds. While they might not present in a manner similar to human TB disease nonetheless they have been very useful to gain knowledge on the way the current treatment is working as well as shed light on the possible 
effects of new drug combinations (De Groote et al., 2011; Grosset et al., 2012). In addition, they have also been used in an effort to mimic more humanised studies to provide valuable information like pharmacokinetics and pharmacodynamics analyses as well as to predict relapse rates following specific drug regiments (Calderon et al., 2013).

\section{Measurement of Patient outcome}

When is a patient cured of tuberculosis? In clinical practice physicians take a practical approach, at the completion of therapy, if the patient is well and have no tubercle bacilli in the sputum then they are deemed cured although they are likely to monitored for a further 12 months to confirm treatment success. This is 18 months after the start of treatment. Thus, when evaluating a new drug or regimen, this standard has to be applied: smear negativity and good health at 18 months; given the time for recruitment of patients to a clinical trial and the time to complete diagnostic procedures on the last sample, a minimum of 3 years must be allowed for any phase 3 study. To address this issue Jindani (Jindani et al., 1980) developed a shortened protocol for rapid evaluation of drug efficacy in phase 2 studies. The Early Bactericidal Activity (EBA), monitors killing of bacteria expressed in sputum over the first 2 weeks of treatment. The rate of killing (termed the EBA) has proven a useful, though imperfect, surrogate of drug efficacy for screening prior to commitment to full Phase 2a or 3 studies (Wallis et al., 2000). In studies of the full treatment course data is often reviewed at the end of the intensive phase or at the completion of treatment, however, evidence is accruing that suggests caution is necessary in this context. In 2 recent studies of moxifloxacin containing regimens, the 2 month data would have predicted the wrong outcome when compared to the fully 18 month data (Gillespie et al., 2014; Jindani et al., 2014).

The conventional bacteriological readout is inadequate to provide surrogacy for drug efficacy, and so the search is on for biomarkers for treatment outcome (Perrin et al., 2007). Clinical signs tend to lack specificity, although improved rigorous approaches to reporting radiological findings do seem to have a role to play (Lin et al., 2013). However, host responses may prove useful; evidence of the changing immunological signature through treatment may provide a tractable biomarker set (Bloom et al., 2013; Peterson et al., 2015). Evidence that bacterial load may be of value is accruing and the improvement in automated culture techniques such as the MGIT (Becton Dickenson) together with molecular tools such as the mycobacterial load assay (MBL; (Honeyborne et al., 2011)) suggest that this biomarker may be informative and practical. Furthermore, the use of culture (either liquid or solid) as well as the application of molecular assays as a way of monitoring TB treatment has enhanced the ability to measure accurately patient's outcomes. GeneXpert MTB/RIF (Cepheid) is a tool that has revolutionised the diagnosis of TB as well as MDRTB by detecting in a single cartridge format, the present of $M$. tuberculosis DNA and possible rifampicin conferring resistant mutations in the $r p o B$ gene. Although GeneXpert is excellent in diagnosing TB cases, its application as a treatment monitoring tool is not reliable compared 
to liquid or solid culture data (Kayigire et al., 2013), due to the fact that it detects mycobacterial DNA that tends to reside in the human tissues for longer period of times following the eradication of bacteria. In this respect, the MBL assay seem to be a better measurement as it detects ribosomal RNA that its decrease correlates better with the reduction of mycobacterial populations due to effect of chemotherapy. In addition, the data of the MBL assay are in good agreement when compared to both liquid culture (MGIT) and solid CFU measurements during a two-week EBA study (Honeyborne et al., 2014) as well as during current clinical trials (unpublished data).

\section{The way forward: solutions}

Over the recent years a considerable knowledge of the basic biology of $M$. tuberculosis infection has been studied. Important elements of the TB pathogenesis have been better understood and we are now almost certain that we should approach TB as a polymicrobial infection. It is now been consider as general practice during the preclinical drug discovery phase that in order to identify potent $M$. tuberculosis growth inhibitors a more systematic approach is required using a variety of models in order to pinpoint an inhibitor that will have an effect at the different physiological states of the bacteria.

\section{In vitro studies}

Starting from in vitro models, the emphasis is to utilise, in addition to actively dividing bacteria, the low metabolically active states during the drug screening processes. This approach will result on identifying more potent inhibitors with a wide range of activities on different sub-population of $M$. tuberculosis. Furthermore, screens of macrophages infected with $M$. tuberculosis are also being employed in a high-throughput manner and they were able to identify potent compounds that are activated within the macrophage environment. One of these compounds is the recently developed lead molecule SQ203 that belong to the class of imidazopyridine amide compounds and inhibits the cytochrome bc1 complex of $M$. tuberculosis and has activity against MDR and XDRTB (Pethe et al., 2013).

However, one of the disadvantages with whole cell phenotypic screens is that the mechanism of action of the newly identified compounds is poorly known. Still, a targetbased approach where a specific protein (usually an enzyme) is specifically inhibited has been widely used with very little outcomes of generating lead molecules for further development (Sams-Dodd, 2005). The main reason for this is that although the molecules inhibit the protein (ie. target) in the assay tube, they fail to achieve similar inhibition that will result in bacterial death in a whole cell system. Nevertheless it is equally important to know the molecular targets of novel compounds that exhibit bacterial growth inhibition so that medicinal chemists can modify accordingly to improve the toxicity, pharmacokinetic and pharmacodynamic characteristics of the lead molecule. 
Traditionally generation of resistant mutants and DNA sequencing was the method of choice in order to deconvolute the molecular targets of new inhibitors. However this method depends on the availability of resistant mutants and this can be limited in some cases (Gold et al., 2012a; Guzman et al., 2013). The application of whole genome transcriptomics is another alternative way to examine the mechanism of action of new molecules. Specific transcriptomic activity is triggered upon addition of antimicrobials in an effort to provide homeostasis back in the bacterial cell. Examining these specific differential gene expression changes can be utilised to predict which metabolic pathways and protein encoding genes that are involved are specifically affected from the antimicrobial compound. Boshoff et al., have shown that by applying hierarchical clustering algorithms to the gene profiling signatures you can interpret the mechanism of action of specific inhibitors (Boshoff et al., 2004). Following this strategy, you can also determine that any of the chemical analogues and modifications of the starting hit are also targeting the same pathway or enzymatic target(s) by using a minimum sub set of genes that their expression data are representative of metabolic action changes using a microfluidic device (Murima et al., 2013).

Another approach where the use of transcriptomic signatures has great potential is to define the state of the different physiology of the bacterial under investigation. Applying transcriptomic analyses on a variety of different whole cell models representing dormant phenotypes upon addition of drugs can revolutionise and increase our knowledge of how these drugs are actually inhibiting or killing low metabolically active bacteria. Using this methodology alongside the traditional screening can also further identify the characteristics of these difficult to treat populations and elucidate its state and response to drug treatment. This vital information will then be transformed into a more clinical set up where the chemotherapy of TB patients can be monitored using transcriptomic gene profiling as a biomarker for drug efficacy and identification of the existence of these different $M$. tuberculosis subpopulations in the clinical specimens.

However one of the main limitations that gene profiling methodologies encounter in drug discovery process is that the measured signal is usually a result of a bacterial population rather than a single cell. To overcome this challenge, various single cell analyses including transcriptomics are currently employed. In the recent years there have been assay development of RNA sequencing derived from single cells and it is almost certain that these methodologies will minimize the heterogeneity on the signals obtain from a mixed population or a population at equilibrium. Furthermore, labelling of specific transcripts as well as real time monitoring using microfluidic devices also provides an alternative solution to study single cell effects and has been recently utilised to study the delayed bactericidal activity of bedaquiline (Koul et al., 2014). Among transcriptomic and proteomic approaches, Koul et al., showed using single cell time lapse microscopy in a microfluidic device the addition of bedaquiline promotes a coordinated metabolic switch in order to enable a transient survival of $M$. tuberculosis bacteria. 
These technological developments will enhance the use of such 'omics' methodologies in a high-throughput format allowing analyses in the drug discovery of TB as well as other infectious diseases.

\section{In vivo studies}

Following the identification of suitable lead molecules and prior to clinical trials, drugs need to undergo a series of animal studies to characteristise drug dosage, toxicity, pharmacokinetics and pharmacodynamics for the first time. In addition, the use of animal models will also be applied to determine successful or synergistic drug combinations. Even though animal models may not always be representative of the human outcome; they are useful to gain preliminary information on drug efficacy. Conventionally, the outcome of the animal experiments will be the measurement of bacterial load and how this is affected by chemotherapy, usually calculated using microbiological methods such as CFU counting on agar plates,. However, in order to extract maximum information on the drug action other biomarkers should also be employed. The MBL assay is a good example that can capture subpopulations of $M$. tuberculosis that are not culturable on agar-based media (Honeyborne et al., 2011). Furthermore, recovery of live bacilli using liquid culture systems with the addition of culture supernatants that contain rpfs will enable a specific rpf-depended subpopulation of bacteria to grow (Turapov et al., 2014). Additional RNA biomarkers can provide a more thorough picture of the population dynamics of bacterial reduction. Transcriptomic profiling has been applied in the past and was able to predict specific patterns based on the disease progression (Bloom et al., 2013; Bloom et al., 2012). This mainly holds true for host derived transcriptomic messages and very little work is performed towards evaluating the pathogen transcriptomic signatures and its dynamics during infection and following chemotherapy.

Furthermore, recent advantages in imaging as well as fluorescent markers that are employed by animal experimentalists are pioneering in providing real time observation of the state and disease progression (Andreu et al., 2013). Medical imaging such as PET-CT and MRI scans that have been traditionally used in humans are currently being transformed into animal experiments (Bagci et al., 2013). This provides several different biomarkers for monitoring the real time development of the disease as well as its treatment rather than just calculating bacterial load following necrosis of the animal. Moreover, the molecular engineering of laboratory strains of $M$. tuberculosis capable of expressing fluorescent proteins enabled to study the co-localisation and granuloma formations (Lin et al., 2013; Manina et al., 2015). Innovative research in non-human primates using these modified microorganisms shed light into latent infection and the immunological nature of the granuloma structures. 
Another aspect that animal models are very informative is on studies on drug delivery. In addition to pharmacokinetics and pharmacodynamics data obtained from serum samples, it is also important to investigate the drug delivery and concentration in tissues and similarly within different types of granulomas where $M$. tuberculosis is well protected from chemotherapy action. Adaptation and further development of traditional methods such as MALDI-TOF Mass Spectroscopy are currently applied to study the drug distribution in tissues as well as its concentration providing an extra important parameter on the drug dynamics (Dartois, 2014).

\section{Clinical studies}

Although the recent phase 3 clinical trials failed to achieve non-inferiority margins and thus they were not able to show efficient shortening of the treatment of TB, they however provide with useful insight on the pathology and chemotherapy of TB (Gillespie et al., 2014; Jindani et al., 2014). These trials were conducted at very high laboratory standards and will aid in our understanding of how the currently six month drug regiment for TB is successful to eliminate the causing bacterium but also provide more insights on the different killing effect and the populations that are affected over the period of treatment. Future TB trials as well as basic research in this field will be highly benefited by the outcomes of these current published clinical trials.

\section{Other recourses - drug repurposing}

Another source of active molecules against TB as well as other infectious diseases is repurposing currently available drugs that have been licenced for diseases other than TB. This strategy has received recent attention for its likelihood to reduce production expenses, lower the risks of clinical toxicity failures and shorten the overall time required for regulatory bodies' approval in order to launch a drug in the market. There are many drugs that have been effectively repositioned to treating another disease (Ashburn and Thor, 2004). The introduction of the fluoroquinolones in the 1980s is one of the first examples of drug repurposing in TB; followed by more recently, thioridazine (Amaral et al., 2010), as well as non-steroidal anti-inflammatory drugs like ibuprofen and oxyphenbutazone (Gold et al., 2012b; Guzman et al., 2013). These already established drugs form a new arsenal towards the increased level of drug resistant strains and this strategy has open new avenues for discovering a differential bacterial target of current therapeutics (Palomino and Martin, 2013).

\section{Conclusions and future directions}

We understand that developing a newly identified hit molecule into a drug candidate against TB is a lengthy process with multiple hurdles to be overcome. The hit molecules will require several evaluation steps and cycles in their development to confirm efficacy. There is an urgent need to evaluate and develop models to predict drug efficacy as early as in vitro 
studies and together with optimised in vivo experimentation provide insufficient information for prediction of clinical efficacy in the TB drug pipeline. Furthermore, the current and future clinical data are essential to be linked with the outcomes of the preclinical evaluations to ensure that an optimised lead molecule will be selected for further analysis. One way that this can be achieved is by modelling the clinical data with the preclinical profiles of the new drugs to in an attempt to create a predictive assay where the clinical outcomes of new compounds as well as different drug combinations will be evaluated. The PreDiCT-TB consortium supported by the European Union has formed with this as its primary aim and to evaluate current preclinical models and integrate them with available clinical data in an effort to make new predictions of effective drug candidates as well as drug combinations.

An integrative approach is required for the development of new drugs against TB and this will include:

a) The utilisation of a variety of biological models that will capture the different metabolic states of $M$. tuberculosis during human disease.

b) The application and further development of single cell analyses in different population studies and the rising of microfluidic devices that will enable these experiments.

c) Adaptation of animal models to humanised experiments as well as implementation of techniques that will allow for real time monitoring of the disease progression and treatment.

d) Development of mathematical models for successful drug prioritisation towards clinical trials based on existing in vitro, in vivo and clinical data.

e) Utilisation of new biomarkers of treatment success during clinical trials and treatment monitoring.

Applying all these complex but feasible approaches will enhance our chances of developing new agents and drug regimes that will be effective against $M$. tuberculosis infections.

\section{Acknowledgements:}

DE and TMcH are part of the PreDiCT-TB consortium (http://www.predict-tb.eu) which is funded from the Innovative Medicines Initiative Joint Undertaking (http://www.imi.europa.eu) under grant agreement No 115337, resources of which are composed of financial contribution from the European Union's Seventh Framework Programme (FP7/2007-2013) and EFPIA companies' in kind contribution. TMcH is part of the PanACEA Consortium for TB drug development funded by the European and Developing Countries Clinical Trials Partnership, grant IP.2007.32011.013. 


\section{References:}

Amaral, L., Boeree, M.J., Gillespie, S.H., Udwadia, Z.F., van Soolingen, D., 2010. Thioridazine cures extensively drug-resistant tuberculosis (XDR-TB) and the need for global trials is now! International journal of antimicrobial agents $35,524-526$.

Amaral, L., Viveiros, M., 2012. Why thioridazine in combination with antibiotics cures extensively drug-resistant Mycobacterium tuberculosis infections. International journal of antimicrobial agents 39, 376-380.

Andreu, N., Zelmer, A., Sampson, S.L., Ikeh, M., Bancroft, G.J., Schaible, U.E., Wiles, S., Robertson, B.D., 2013. Rapid in vivo assessment of drug efficacy against Mycobacterium tuberculosis using an improved firefly luciferase. Journal of Antimicrobial Chemotherapy 68, 2118-2127.

Armstrong, J.A., Hart, P.D., 1975. Phagosome-lysosome interactions in cultured macrophages infected with virulent tubercle bacilli. Reversal of the usual nonfusion pattern and observations on bacterial survival. J Exp Med 142, 1-16.

Ashburn, T.T., Thor, K.B., 2004. Drug repositioning: identifying and developing new uses for existing drugs. Nat Rev Drug Discov 3, 673-683.

Bagci, U., Foster, B., Miller-Jaster, K., Luna, B., Dey, B., Bishai, W.R., Jonsson, C.B., Jain, S., Mollura, D.J., 2013. A computational pipeline for quantification of pulmonary infections in small animal models using serial PET-CT imaging. EJNMMI research 3, 55.

Betts, J.C., Lukey, P.T., Robb, L.C., McAdam, R.A., Duncan, K., 2002. Evaluation of a nutrient starvation model of Mycobacterium tuberculosis persistence by gene and protein expression profiling. Molecular microbiology 43, 717-731.

Bloom, C.I., Graham, C.M., Berry, M.P., Rozakeas, F., Redford, P.S., Wang, Y., Xu, Z., Wilkinson, K.A., Wilkinson, R.J., Kendrick, Y., Devouassoux, G., Ferry, T., Miyara, M., Bouvry, D., Valeyre, D., Gorochov, G., Blankenship, D., Saadatian, M., Vanhems, P., Beynon, H., Vancheeswaran, R., Wickremasinghe, M., Chaussabel, D., Banchereau, J., Pascual, V., Ho, L.P., Lipman, M., O'Garra, A., 2013. Transcriptional blood signatures distinguish pulmonary tuberculosis, pulmonary sarcoidosis, pneumonias and lung cancers. PloS one 8, e70630.

Bloom, C.I., Graham, C.M., Berry, M.P., Wilkinson, K.A., Oni, T., Rozakeas, F., Xu, Z., Rossello-Urgell, J., Chaussabel, D., Banchereau, J., Pascual, V., Lipman, M., Wilkinson, R.J., O'Garra, A., 2012.

Detectable changes in the blood transcriptome are present after two weeks of antituberculosis therapy. PloS one 7, e46191.

Boshoff, H.I., Myers, T.G., Copp, B.R., McNeil, M.R., Wilson, M.A., Barry, C.E., 3rd, 2004. The transcriptional responses of Mycobacterium tuberculosis to inhibitors of metabolism: novel insights into drug mechanisms of action. The Journal of biological chemistry 279, 40174-40184.

Calderon, V.E., Valbuena, G., Goez, Y., Judy, B.M., Huante, M.B., Sutjita, P., Johnston, R.K., Estes, D.M., Hunter, R.L., Actor, J.K., Cirillo, J.D., Endsley, J.J., 2013. A humanized mouse model of tuberculosis. PloS one 8, e63331.

Cohen-Gonsaud, M., Barthe, P., Bagneris, C., Henderson, B., Ward, J., Roumestand, C., Keep, N.H., 2005. The structure of a resuscitation-promoting factor domain from Mycobacterium tuberculosis shows homology to lysozymes. Nat Struct Mol Biol 12, 270-273.

Cohen, Nadia R., Lobritz, Michael A., Collins, James J., 2013. Microbial Persistence and the Road to Drug Resistance. Cell host \& microbe 13, 632-642.

Cole, S.T., Brosch, R., Parkhill, J., Garnier, T., Churcher, C., Harris, D., Gordon, S.V., Eiglmeier, K., Gas, S., Barry, C.E., 3rd, Tekaia, F., Badcock, K., Basham, D., Brown, D., Chillingworth, T., Connor, R., Davies, R., Devlin, K., Feltwell, T., Gentles, S., Hamlin, N., Holroyd, S., Hornsby, T., Jagels, K., Krogh, A., McLean, J., Moule, S., Murphy, L., Oliver, K., Osborne, J., Quail, M.A., Rajandream, M.A., Rogers, J., Rutter, S., Seeger, K., Skelton, J., Squares, R., Squares, S., Sulston, J.E., Taylor, K., Whitehead, S., Barrell, B.G., 1998. Deciphering the biology of Mycobacterium tuberculosis from the complete genome sequence. Nature 393, 537-544. 
Dartois, V., 2014. The path of anti-tuberculosis drugs: from blood to lesions to mycobacterial cells. Nat Rev Micro 12, 159-167.

Davies, A.P., Dhillon, A.P., Young, M., Henderson, B., McHugh, T.D., Gillespie, S.H., 2008.

Resuscitation-promoting factors are expressed in Mycobacterium tuberculosis-infected human tissue. Tuberculosis (Edinb) 88, 462-468.

De Groote, M.A., Gilliland, J.C., Wells, C.L., Brooks, E.J., Woolhiser, L.K., Gruppo, V., Peloquin, C.A., Orme, I.M., Lenaerts, A.J., 2011. Comparative studies evaluating mouse models used for efficacy testing of experimental drugs against Mycobacterium tuberculosis. Antimicrobial agents and chemotherapy $55,1237-1247$.

Deb, C., Lee, C.M., Dubey, V.S., Daniel, J., Abomoelak, B., Sirakova, T.D., Pawar, S., Rogers, L., Kolattukudy, P.E., 2009. A novel in vitro multiple-stress dormancy model for Mycobacterium tuberculosis generates a lipid-loaded, drug-tolerant, dormant pathogen. PloS one 4, e6077. Fenhalls, G., Stevens, L., Moses, L., Bezuidenhout, J., Betts, J.C., Helden Pv, P., Lukey, P.T., Duncan, K., 2002. In situ detection of Mycobacterium tuberculosis transcripts in human lung granulomas reveals differential gene expression in necrotic lesions. Infection and immunity 70, 6330-6338. Fuller, C.L., Flynn, J.L., Reinhart, T.A., 2003. In situ study of abundant expression of proinflammatory chemokines and cytokines in pulmonary granulomas that develop in cynomolgus macaques experimentally infected with Mycobacterium tuberculosis. Infection and immunity 71, 7023-7034. Galagan, J.E., Minch, K., Peterson, M., Lyubetskaya, A., Azizi, E., Sweet, L., Gomes, A., Rustad, T., Dolganov, G., Glotova, I., Abeel, T., Mahwinney, C., Kennedy, A.D., Allard, R., Brabant, W., Krueger, A., Jaini, S., Honda, B., Yu, W.-H., Hickey, M.J., Zucker, J., Garay, C., Weiner, B., Sisk, P., Stolte, C., Winkler, J.K., Van de Peer, Y., lazzetti, P., Camacho, D., Dreyfuss, J., Liu, Y., Dorhoi, A., Mollenkopf, H.-J., Drogaris, P., Lamontagne, J., Zhou, Y., Piquenot, J., Park, S.T., Raman, S., Kaufmann, S.H.E., Mohney, R.P., Chelsky, D., Moody, D.B., Sherman, D.R., Schoolnik, G.K., 2013. The Mycobacterium tuberculosis regulatory network and hypoxia. Nature 499, 178-183.

Garton, N.J., Waddell, S.J., Sherratt, A.L., Lee, S.M., Smith, R.J., Senner, C., Hinds, J., Rajakumar, K., Adegbola, R.A., Besra, G.S., Butcher, P.D., Barer, M.R., 2008. Cytological and transcript analyses reveal fat and lazy persister-like bacilli in tuberculous sputum. PLoS medicine 5, e75.

Gillespie, S.H., Crook, A.M., McHugh, T.D., Mendel, C.M., Meredith, S.K., Murray, S.R., Pappas, F., Phillips, P.P., Nunn, A.J., 2014. Four-month moxifloxacin-based regimens for drug-sensitive tuberculosis. The New England journal of medicine 371, 1577-1587.

Gold, B., Pingle, M., Brickner, S.J., Shah, N., Roberts, J., Rundell, M., Bracken, W.C., Warrier, T., Somersan, S., Venugopal, A., Darby, C., Jiang, X., Warren, J.D., Fernandez, J., Ouerfelli, O., Nuermberger, E.L., Cunningham-Bussel, A., Rath, P., Chidawanyika, T., Deng, H., Realubit, R., Glickman, J.F., Nathan, C.F., 2012b. Nonsteroidal anti-inflammatory drug sensitizes Mycobacterium tuberculosis to endogenous and exogenous antimicrobials. Proceedings of the National Academy of Sciences of the United States of America 109, 16004-16011.

Grosset, J., Almeida, D., Converse, P.J., Tyagi, S., Li, S.Y., Ammerman, N.C., Pym, A.S., Wallengren, K., Hafner, R., Lalloo, U., Swindells, S., Bishai, W.R., 2012. Modeling early bactericidal activity in murine tuberculosis provides insights into the activity of isoniazid and pyrazinamide. Proceedings of the National Academy of Sciences of the United States of America 109, 15001-15005.

Guzman, J.D., Evangelopoulos, D., Gupta, A., Birchall, K., Mwaigwisya, S., Saxty, B., McHugh, T.D., Gibbons, S., Malkinson, J., Bhakta, S., 2013. Antitubercular specific activity of ibuprofen and the other 2-arylpropanoic acids using the HT-SPOTi whole-cell phenotypic assay. BMJ Open 3.

Guzman, J.D., Evangelopoulos, D., Gupta, A., Prieto, J.M., Gibbons, S., Bhakta, S., 2012.

Antimycobacterials from Lovage Root (Ligusticum officinale Koch). Phytotherapy research : PTR. Guzman, J.D., Gupta, A., Evangelopoulos, D., Basavannacharya, C., Pabon, L.C., Plazas, E.A., Munoz, D.R., Delgado, W.A., Cuca, L.E., Ribon, W., Gibbons, S., Bhakta, S., 2010. Anti-tubercular screening of natural products from Colombian plants: 3-methoxynordomesticine, an inhibitor of MurE ligase of Mycobacterium tuberculosis. The Journal of antimicrobial chemotherapy 65, 2101-2107. 
Guzman, J.D., Wube, A., Evangelopoulos, D., Gupta, A., Hufner, A., Basavannacharya, C., Rahman, M.M., Thomaschitz, C., Bauer, R., McHugh, T.D., Nobeli, I., Prieto, J.M., Gibbons, S., Bucar, F., Bhakta, $\mathrm{S} ., 2$ 2011. Interaction of $\mathrm{N}$-methyl-2-alkenyl-4-quinolones with ATP-dependent MurE ligase of Mycobacterium tuberculosis: antibacterial activity, molecular docking and inhibition kinetics. The Journal of antimicrobial chemotherapy 66, 1766-1772.

Honeyborne, I., McHugh, T.D., Phillips, P.P., Bannoo, S., Bateson, A., Carroll, N., Perrin, F.M., Ronacher, K., Wright, L., van Helden, P.D., Walzl, G., Gillespie, S.H., 2011. Molecular bacterial load assay, a culture-free biomarker for rapid and accurate quantification of sputum Mycobacterium tuberculosis bacillary load during treatment. Journal of clinical microbiology 49, 3905-3911. Honeyborne, I., Mtafya, B., Phillips, P.P., Hoelscher, M., Ntinginya, E.N., Kohlenberg, A., Rachow, A., Rojas-Ponce, G., McHugh, T.D., Heinrich, N., 2014. The molecular bacterial load assay replaces solid culture for measuring early bactericidal response to antituberculosis treatment. Journal of clinical microbiology 52, 3064-3067.

Hu, Y., Butcher, P., Sole, K., Mitchison, D., Coates, A., 1998. Protein synthesis is shutdown in dormant Mycobacterium tuberculosis and is reversed by oxygen or heat shock. FEMS microbiology letters 158, 139 - 145.

Jindani, A., 1976. Short-course (6-month) treatment of pulmonary tuberculosis (Second East African/British Medical Research Council Study). Bulletin of the International Union against Tuberculosis 51, 53-56.

Jindani, A., Aber, V.R., Edwards, E.A., Mitchison, D.A., 1980. The early bactericidal activity of drugs in patients with pulmonary tuberculosis. The American review of respiratory disease 121, 939-949.

Jindani, A., Harrison, T.S., Nunn, A.J., Phillips, P.P., Churchyard, G.J., Charalambous, S., Hatherill, M., Geldenhuys, H., Mcllleron, H.M., Zvada, S.P., Mungofa, S., Shah, N.A., Zizhou, S., Magweta, L., Shepherd, J., Nyirenda, S., van Dijk, J.H., Clouting, H.E., Coleman, D., Bateson, A.L., McHugh, T.D., Butcher, P.D., Mitchison, D.A., 2014. High-dose rifapentine with moxifloxacin for pulmonary tuberculosis. The New England journal of medicine 371, 1599-1608.

Kana, B.D., Gordhan, B.G., Downing, K.J., Sung, N., Vostroktunova, G., Machowski, E.E., Tsenova, L., Young, M., Kaprelyants, A., Kaplan, G., Mizrahi, V., 2008. The resuscitation-promoting factors of Mycobacterium tuberculosis are required for virulence and resuscitation from dormancy but are collectively dispensable for growth in vitro. Molecular microbiology 67, 672-684.

Kana, B.D., Mizrahi, V., 2010. Resuscitation-promoting factors as lytic enzymes for bacterial growth and signaling. FEMS Immunol Med Microbiol 58, 39-50.

Kayigire, X.A., Friedrich, S.O., Venter, A., Dawson, R., Gillespie, S.H., Boeree, M.J., Heinrich, N., Hoelscher, M., Diacon, A.H., 2013. Direct comparison of Xpert MTB/RIF assay with liquid and solid mycobacterial culture for quantification of early bactericidal activity. Journal of clinical microbiology 51, 1894-1898.

Keep, N.H., Ward, J.M., Cohen-Gonsaud, M., Henderson, B., 2006. Wake up! Peptidoglycan lysis and bacterial non-growth states. Trends in microbiology 14, 271-276.

Keren, I., Minami, S., Rubin, E., Lewis, K., 2011. Characterization and transcriptome analysis of Mycobacterium tuberculosis persisters. mBio 2, e00100-00111.

Kim, M.J., Wainwright, H.C., Locketz, M., Bekker, L.G., Walther, G.B., Dittrich, C., Visser, A., Wang, W., Hsu, F.F., Wiehart, U., Tsenova, L., Kaplan, G., Russell, D.G., 2010. Caseation of human tuberculosis granulomas correlates with elevated host lipid metabolism. EMBO molecular medicine 2, 258-274.

Korbel, D.S., Schneider, B.E., Schaible, U.E., 2008. Innate immunity in tuberculosis: myths and truth. Microbes Infect 10, 995-1004.

Kottakota, S.K., Benton, M., Evangelopoulos, D., Guzman, J.D., Bhakta, S., McHugh, T.D., Gray, M., Groundwater, P.W., Marrs, E.C., Perry, J.D., Harburn, J.J., 2012a. Versatile Routes to Marine Sponge Metabolites through Benzylidene Rhodanines. Organic letters.

Kottakota, S.K., Evangelopoulos, D., Alnimr, A., Bhakta, S., McHugh, T.D., Gray, M., Groundwater, P.W., Marrs, E.C., Perry, J.D., Spilling, C.D., Harburn, J.J., 2012b. Synthesis and biological evaluation 
of purpurealidin E-derived marine sponge metabolites: aplysamine-2, aplyzanzine $A$, and suberedamines $A$ and $B$. Journal of natural products 75, 1090-1101.

Koul, A., Vranckx, L., Dhar, N., Gohlmann, H.W., Ozdemir, E., Neefs, J.M., Schulz, M., Lu, P., Mortz, E., McKinney, J.D., Andries, K., Bald, D., 2014. Delayed bactericidal response of Mycobacterium tuberculosis to bedaquiline involves remodelling of bacterial metabolism. Nature communications 5 , 3369.

Lin, P.L., Coleman, T., Carney, J.P., Lopresti, B.J., Tomko, J., Fillmore, D., Dartois, V., Scanga, C., Frye, L.J., Janssen, C., Klein, E., Barry, C.E., 3rd, Flynn, J.L., 2013. Radiologic responses in cynomolgous macaques for assessing tuberculosis chemotherapy regimens. Antimicrobial agents and chemotherapy.

Manina, G., Dhar, N., McKinney, J.D., 2015. Stress and Host Immunity Amplify Mycobacterium tuberculosis Phenotypic Heterogeneity and Induce Nongrowing Metabolically Active Forms. Cell host \& microbe 17, 32-46.

Marks, G.B., Bai, J., Simpson, S.E., Sullivan, E.A., Stewart, G.J., 2000. Incidence of tuberculosis among a cohort of tuberculin-positive refugees in Australia: reappraising the estimates of risk. American journal of respiratory and critical care medicine 162, 1851-1854.

Mitchison, D., Davies, G., 2012. The chemotherapy of tuberculosis: past, present and future. The international journal of tuberculosis and lung disease : the official journal of the International Union against Tuberculosis and Lung Disease 16, 724-732.

Mitchison, D.A., Jindani, A., Davies, G.R., Sirgel, F., 2007. Isoniazid activity is terminated by bacterial persistence. The Journal of infectious diseases 195, 1871-1872; author reply 1872-1873.

Mukamolova, G.V., Kaprelyants, A.S., Young, D.I., Young, M., Kell, D.B., 1998. A bacterial cytokine. Proceedings of the National Academy of Sciences of the United States of America 95, 8916-8921.

Mukamolova, G.V., Turapov, O., Malkin, J., Woltmann, G., Barer, M.R., 2010. Resuscitationpromoting factors reveal an occult population of tubercle Bacilli in Sputum. American journal of respiratory and critical care medicine 181, 174-180.

Murima, P., Sessions, P.F.d., Lim, V., Naim, A.N.M., Bifani, P., Boshoff, H.I.M., Sambandamurthy, V.K., Dick, T., Hibberd, M.L., Schreiber, M., Rao, S.P.S., 2013. Exploring the Mode of Action of Bioactive Compounds by Microfluidic Transcriptional Profiling in Mycobacteria. PloS one 8, e69191.

O'Donnell, G., Poeschl, R., Zimhony, O., Gunaratnam, M., Moreira, J.B., Neidle, S., Evangelopoulos, D., Bhakta, S., Malkinson, J.P., Boshoff, H.I., Lenaerts, A., Gibbons, S., 2009. Bioactive pyridine-Noxide disulfides from Allium stipitatum. Journal of natural products $72,360-365$.

Osman, K., Evangelopoulos, D., Basavannacharya, C., Gupta, A., McHugh, T.D., Bhakta, S., Gibbons, S., 2012. An antibacterial from Hypericum acmosepalum inhibits ATP-dependent MurE ligase from Mycobacterium tuberculosis. International journal of antimicrobial agents 39, 124-129.

Pablos-Mendez, A., 2000. Working alliance for TB drug development, Cape Town, South Africa, February 8th, 2000. The international journal of tuberculosis and lung disease : the official journal of the International Union against Tuberculosis and Lung Disease 4, 489-490.

Palomino, J.C., Martin, A., 2013. Is repositioning of drugs a viable alternative in the treatment of tuberculosis? J Antimicrob Chemother 68, 275-283.

Pandey, A.K., Sassetti, C.M., 2008. Mycobacterial persistence requires the utilization of host cholesterol. Proceedings of the National Academy of Sciences of the United States of America 105, 4376-4380.

Perrin, F.M., Lipman, M.C., McHugh, T.D., Gillespie, S.H., 2007. Biomarkers of treatment response in clinical trials of novel antituberculosis agents. The Lancet infectious diseases 7, 481-490.

Peterson, E.J., Reiss, D.J., Turkarslan, S., Minch, K.J., Rustad, T., Plaisier, C.L., Longabaugh, W.J., Sherman, D.R., Baliga, N.S., 2015. A high-resolution network model for global gene regulation in Mycobacterium tuberculosis. Nucleic acids research 42, 11291-11303.

Pethe, K., Bifani, P., Jang, J., Kang, S., Park, S., Ahn, S., Jiricek, J., Jung, J., Jeon, H.K., Cechetto, J., Christophe, T., Lee, H., Kempf, M., Jackson, M., Lenaerts, A.J., Pham, H., Jones, V., Seo, M.J., Kim, Y.M., Seo, M., Seo, J.J., Park, D., Ko, Y., Choi, I., Kim, R., Kim, S.Y., Lim, S., Yim, S.A., Nam, J., Kang, H., 
Kwon, H., Oh, C.T., Cho, Y., Jang, Y., Kim, J., Chua, A., Tan, B.H., Nanjundappa, M.B., Rao, S.P., Barnes, W.S., Wintjens, R., Walker, J.R., Alonso, S., Lee, S., Kim, J., Oh, S., Oh, T., Nehrbass, U., Han, S.J., No, Z., Lee, J., Brodin, P., Cho, S.N., Nam, K., Kim, J., 2013. Discovery of Q203, a potent clinical candidate for the treatment of tuberculosis. Nature medicine 19, 1157-1160.

Rhoades, E.R., Cooper, A.M., Orme, I.M., 1995. Chemokine response in mice infected with Mycobacterium tuberculosis. Infection and immunity 63, 3871-3877.

Rosenthal, I.M., Tasneen, R., Peloquin, C.A., Zhang, M., Almeida, D., Mdluli, K.E., Karakousis, P.C., Grosset, J.H., Nuermberger, E.L., 2012. Dose-ranging comparison of rifampin and rifapentine in two pathologically distinct murine models of tuberculosis. Antimicrobial agents and chemotherapy 56 , 4331-4340.

Russell, D.G., Cardona, P.J., Kim, M.J., Allain, S., Altare, F., 2009. Foamy macrophages and the progression of the human tuberculosis granuloma. Nat Immunol 10, 943-948.

Sams-Dodd, F., 2005. Target-based drug discovery: is something wrong? Drug Discovery Today 10, 139-147.

Sim, E., Sandy, J., Evangelopoulos, D., Fullam, E., Bhakta, S., Westwood, I., Krylova, A., Lack, N., Noble, M., 2008. Arylamine $\mathrm{N}$-acetyltransferases in mycobacteria. Current drug metabolism 9, 510519.

Tsai, M.C., Chakravarty, S., Zhu, G., Xu, J., Tanaka, K., Koch, C., Tufariello, J., Flynn, J., Chan, J., 2006. Characterization of the tuberculous granuloma in murine and human lungs: cellular composition and relative tissue oxygen tension. Cell Microbiol 8, 218-232.

Tufariello, J.M., Jacobs, W.R., Jr., Chan, J., 2004. Individual Mycobacterium tuberculosis resuscitation-promoting factor homologues are dispensable for growth in vitro and in vivo. Infection and immunity $72,515-526$.

Tufariello, J.M., Mi, K., Xu, J., Manabe, Y.C., Kesavan, A.K., Drumm, J., Tanaka, K., Jacobs, W.R., Jr., Chan, J., 2006. Deletion of the Mycobacterium tuberculosis resuscitation-promoting factor Rv1009 gene results in delayed reactivation from chronic tuberculosis. Infection and immunity $74,2985-$ 2995.

Turapov, O., Glenn, S., Kana, B., Makarov, V., Andrew, P.W., Mukamolova, G.V., 2014. The in vivo environment accelerates generation of resuscitation-promoting factor-dependent mycobacteria. American journal of respiratory and critical care medicine 190, 1455-1457.

Udwadia, Z.F., 2012. MDR, XDR, TDR tuberculosis: ominous progression. Thorax 67, 286-288. Udwadia, Z.F., Sen, T., Pinto, L.M., 2011. Safety and efficacy of thioridazine as salvage therapy in Indian patients with XDR-TB. Recent patents on anti-infective drug discovery 6, 88-91.

van Crevel, R., Ottenhoff, T.H., van der Meer, J.W., 2002. Innate immunity to Mycobacterium tuberculosis. Clin Microbiol Rev 15, 294-309.

van Ingen, J., Aarnoutse, R.E., Donald, P.R., Diacon, A.H., Dawson, R., Plemper van Balen, G., Gillespie, S.H., Boeree, M.J., 2011. Why Do We Use $600 \mathrm{mg}$ of Rifampicin in Tuberculosis Treatment? Clinical infectious diseases : an official publication of the Infectious Diseases Society of America 52, e194-199.

Wakamoto, Y., Dhar, N., Chait, R., Schneider, K., Signorino-Gelo, F., Leibler, S., McKinney, J.D., 2013. Dynamic Persistence of Antibiotic-Stressed Mycobacteria. Science 339, 91-95.

Wallis, R.S., Kim, P., Cole, S., Hanna, D., Andrade, B.B., Maeurer, M., Schito, M., Zumla, A., 2013. Tuberculosis biomarkers discovery: developments, needs, and challenges. The Lancet infectious diseases 13, 362-372.

Wallis, R.S., Perkins, M.D., Phillips, M., Joloba, M., Namale, A., Johnson, J.L., Whalen, C.C., Teixeira, L., Demchuk, B., Dietze, R., Mugerwa, R.D., Eisenach, K., Ellner, J.J., 2000. Predicting the outcome of therapy for pulmonary tuberculosis. American journal of respiratory and critical care medicine 161, 1076-1080.

Wayne, L.G., Hayes, L.G., 1996. An in vitro model for sequential study of shiftdown of Mycobacterium tuberculosis through two stages of nonreplicating persistence. Infection and immunity 64, 2062-2069. 
WHO, 1993. WHO declares tuberculosis a global emergency World Health Organization, Geneva. WHO, 2013. Global tuberculosis report 2013: WHO report

Young, D., 2009. Animal models of tuberculosis. European Journal of Immunology 39, 2011-2014.

Young, D.B., Perkins, M.D., Duncan, K., Barry, C.E., 3rd, 2008. Confronting the scientific obstacles to global control of tuberculosis. The Journal of clinical investigation 118, 1255-1265.

Zumla, A., Nahid, P., Cole, S.T., 2013. Advances in the development of new tuberculosis drugs and treatment regimens. Nature reviews. Drug discovery 12, 388-404.

Zumla, A.I., Gillespie, S.H., Hoelscher, M., Philips, P.P., Cole, S.T., Abubakar, I., McHugh, T.D., Schito, M., Maeurer, M., Nunn, A.J., 2014a. New antituberculosis drugs, regimens, and adjunct therapies: needs, advances, and future prospects. The Lancet infectious diseases 14, 327-340.

Zumla, A.I., Schito, M., Maeurer, M., 2014b. Advancing the portfolio of tuberculosis diagnostics, drugs, biomarkers, and vaccines. The Lancet infectious diseases 14, 267-269. 